\title{
ELLMAN'S REAGENT FOR ANALYSIS OF $o$-CHLOROBENZYLIDENE MALONONITRILE (CS RIOT CONTROL AGENT) IN SOLID SAMPLES
}

\author{
VLADIMÍR PITSCHMANN ${ }^{1,2}$, LUKÁŠ MATĚJOVSKÝz*AND ZBYNĚKK KOBLIHA

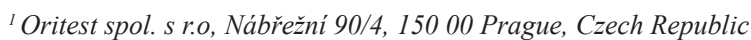 \\ ${ }^{2}$ Czech Technical University in Prague, Faculty of Biomedical Engineering, nám. Sítná 3105, 27201 Kladno, Czech Republic \\ ${ }^{3}$ Faculty of Environmental Technology, University of Chemistry and Technology, Technická 5, 16628 Prague, Czech Republic \\ ${ }^{4}$ NBC Defence Institute, University of Defence, Kounicova 156, 66210 Brno, Czech Republic
}

\begin{abstract}
We propose a new method of spectrophotometric determination of $o$-chlorobenzylidene malononitrile (CS riot control agent) in solid samples of various origins and compositions (soil, brickwork, silica gel, glass wool). The method is based on colouring reaction of malononitrile with Ellman's reagent in the presence of ammonium acetate as a catalyst. The reaction proceeds in a non-aqueous medium. The analysis takes place in an aprotic solvent $N, N$-dimethylformamide, which is also an extraction reagent. A detection limit is $0.18 \mu \mathrm{g} \mathrm{mL}^{-1}$, calibration curve is linear in the range of $0.34-10.20 \mu \mathrm{g} \mathrm{mL}$. The method is suitable for an analysis in laboratory as well as in field conditions.
\end{abstract}

Keywords: riot control agent; environmental analysis; forensic analysis; spectrophotometry; Ellman's reagent.

\section{INTRODUCTION}

$o$-Chlorobenzylidene malononitrile (CS) is in the pure state a white crystal substance that is characterised by highly irritating effect on the mucous membranes of eyes, respiratory tract and skin. In the past, it was introduced as a non-lethal chemical weapon; nowadays, it is used mainly for police purpose as a riot control agent (sometimes described as "tear gas"), for self-defence, to test the tightness of protective masks and during training. CS is usually applied (mostly with other irritating agents) as toxic fume or liquid aerosol. An inhalation incapacitating concentration (ICt $t_{50}$ ) is 10 to $20 \mathrm{mg} \mathrm{min} \mathrm{m}^{-3}$ and the lethal concentration $\left(L C t_{50}\right)$ is approximately $61,000 \mathrm{mg} \mathrm{min}^{-3}$. A volatility of $\mathrm{CS}$ is $0.7 \mathrm{mg} \mathrm{m}^{-3}\left(25^{\circ} \mathrm{C}\right)$. It is partially soluble in water (approximately $2 \%$ ) and slowly hydrolyses to $o$-chlorobenzaldehyde and malononitrile. The persistence in terrain differs from several days to weeks depending on a contaminated material (soil, brickwork, etc.). The specially adjusted formulations (CS2) can contaminate the terrain for a long period ${ }^{1-3}$.

CS analysis is important in the fields of NBC individual protection, hygiene, the quality of environment or forensic sciences. A lot of instrumental methods have been described concerning this purpose, for example chemiluminescence ${ }^{4}$, IR spectrometry ${ }^{5}$, gas chromatography in the combination with various detectors ${ }^{6-8}$ or liquid chromatography ${ }^{9}$. Concerning military practice (chemical reconnaissance and chemical control), an important role is also played by colorimetric and spectrophotometric methods using colouring reactions with various reagents ${ }^{10}$. In laboratory as well as in field conditions, the reactions of CS with 1,3-dinitrobenzene ${ }^{11}$, benzoquinones (e.g. chloranil) ${ }^{12}$, ninhydrin ${ }^{10}$, sodium nitroprusside ${ }^{10}$, Marquis reagent ${ }^{13}$ or $4-\left(4^{\prime}\right.$-nitrobenzyl)pyridine ${ }^{14}$ can be used as well. Several other reactions were described as well, such as oxidation of CS while loosening cyanides, which can be proven by the reaction with polymethine dyes ${ }^{10}$, reaction of CS with benzofuran derivatives ${ }^{15,16}$, or extraction spectrophotometric determination of CS using stabilised diazonium salts ${ }^{17}$. A disadvantage of most of these methods is the disturbing influence of other commonly used riot control agents, particularly chloroacetophenone, and their low sensitivity.

The aim of the presented paper is to describe a spectrophotometric determination of CS in solid samples using Ellman's reagent, i.e. 5,5'-dithiobis(2-nitrobenzoic acid). Previously, we have suggested this reagent for detection of CS in the air using a detector tube, which contains chemi-sorption layer saturated with reagent, and ampoule filled with an aprotic solvent dimethyl sulfoxide (DMSO). ${ }^{18}$ The spectrophotometric method uses the reaction of CS with Ellman's reagent catalysed by ammonium acetate in an aprotic solvent $\mathrm{N}, \mathrm{N}$-dimethylformamide (DMF). This newly proposed method is characterized by high sensitivity and resistance to interferences of other riot control agents.

\section{EXPERIMENTAL}

\subsection{Chemicals and equipment}

During the study, following chemicals were used: Ellman's reagent, ammonium acetate, DMF (all Sigma-Aldrich-Fluka) were used. The used chemicals have at least analytical purity. 98\% CS (Syntchem, Slovakia) was used as a standard. The purity of the standard was verified by the reaction with an excess of a standard solution of $\mathrm{KCN}$ in the presence of $\mathrm{KHCO}_{3}$; the unconsumed cyanide was determined by an $0.1 \mathrm{M}$ standard solution of $\mathrm{AgNO}_{3}$. The stock solution was prepared by dissolving $0.1 \mathrm{~g}$ of CS in DMF. The final solutions were prepared by diluting the stock solution. Fine-grained soil (clay, particles $0.002-0.06 \mathrm{~mm}$ ), coarse-grained soil (sand, particles $0.06-$ $2.0 \mathrm{~mm}$ ), brickwork (brick with plaster), silica gel with graining $0.4-0.5 \mathrm{~mm}$ with measurable surface $200 \mathrm{~m}^{2} \mathrm{~kg}^{-1}$ (Grace, Germany) and glass wool adjusted by silane (Chromatography Research Supplies, USA) were used as samples of solid materials. Spectrophotometric measurements were performed using a spectrophotometer Aquamate (Thermo Spectronic, UK).

\subsection{Basic procedure of spectrophotometric development}

Into $1 \mathrm{~mL}$ of CS sample in DMF, following chemicals were added: $0.1 \mathrm{~mL}$ of $0.4 \%$ Ellman's reagent in DMF and $0.5 \mathrm{~mL}$ of saturated solution of ammonium acetate in DMF. Then, DMF was added up to $2 \mathrm{~mL}$. After 5 minutes, the absorbance of the solution was measured against at $501 \mathrm{~nm}$. The kinetics of the reaction, the ratio of the reagents, the interference and other parameters were studied in a usual way ${ }^{19}$.

\subsection{Preparation of sample and its analysis}

The samples were prepared with a given amount of a material (soil, sand, brickwork, silica gel, glass wool) being contaminated by an exactly measured amount of CS solved in chloroform. The superfluous chloroform was freely evaporated into the air. Approximately $5 \mathrm{~g}$ of a homogenised sample were inserted into a flask, poured over by $10 \mathrm{~mL}$ of DMF and extracted by shaking for 10 minutes. The extract was repeatedly (twice) filtered and if containing water, it was dried by $1.0 \mathrm{~g}$ of sodium sulphate (for 30 minutes). The extract treated this way was transferred into a test tube and used for the further analysis according to the basic procedure of spectrophotometric measuring.

\section{RESULTS AND DISCUSSION}

\subsection{Characterising dying}

The mechanism of the analytical reaction (in a non-aqueous medium) has not been examined in detail yet. Most likely, it is based on the catalytic dissociation of CS forming malononitrile, which in the aprotic solvent DMF decomposes Ellman's reagent into colourful 5-thio-2-nitrobenzoic acid (Scheme $1)$. The reaction product had the absorption maximum at the wavelength of $\lambda_{\text {max }}=501 \mathrm{~nm}$. The absorption curve is shown in Figure 1, from which it is evident that the use of DMF caused a shift of wavelength of the maximum absorbance of 5-thio-2-nitrobenzoic acid as reaction product in comparison to medium water / ethanol (reaction of Ellman's reagent with sodium sulphide). 
The solution was fully colored in 5 minutes and the colouration was stable and suitable for measuring for at least 30 minutes (Figure 2).
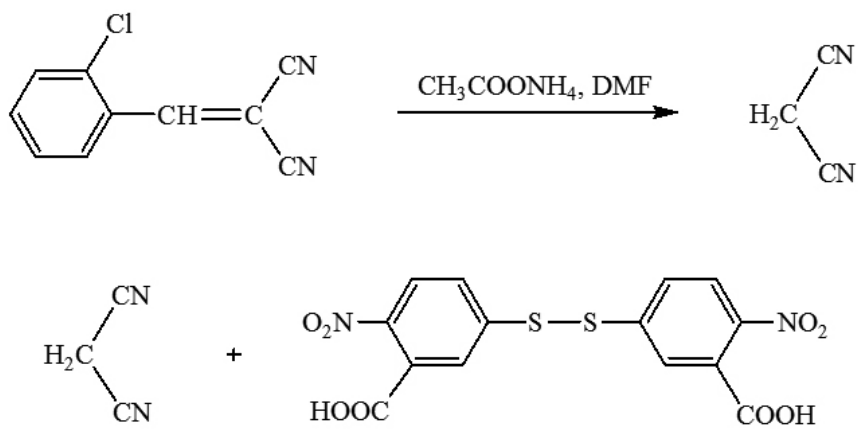

DMF

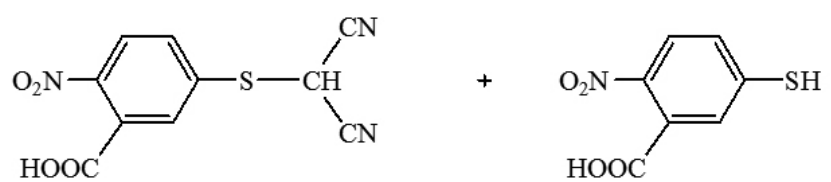

Scheme 1. Reaction scheme of CS and Ellman's reagent

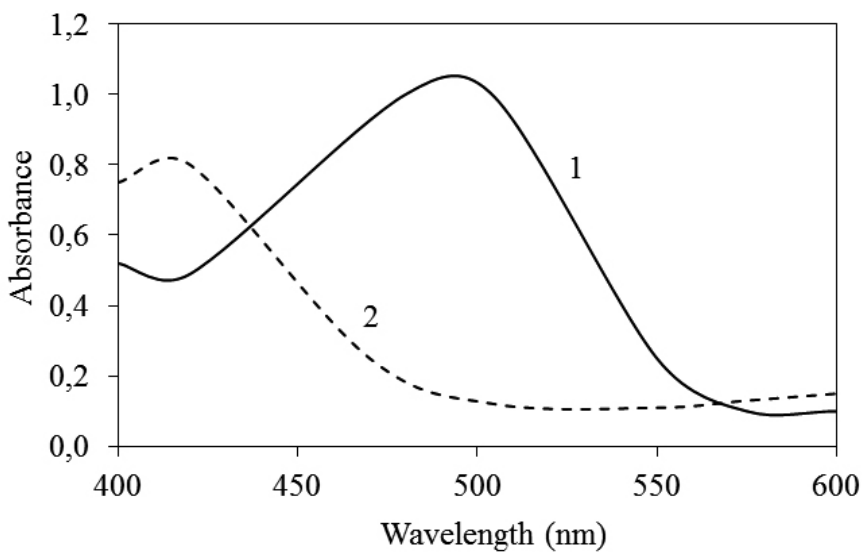

Figure 1. Absorption curve of 5-thio-2-nitrobenzoic acid as the reaction product $(1-$ in DMF, 2 - in water / ethanol).

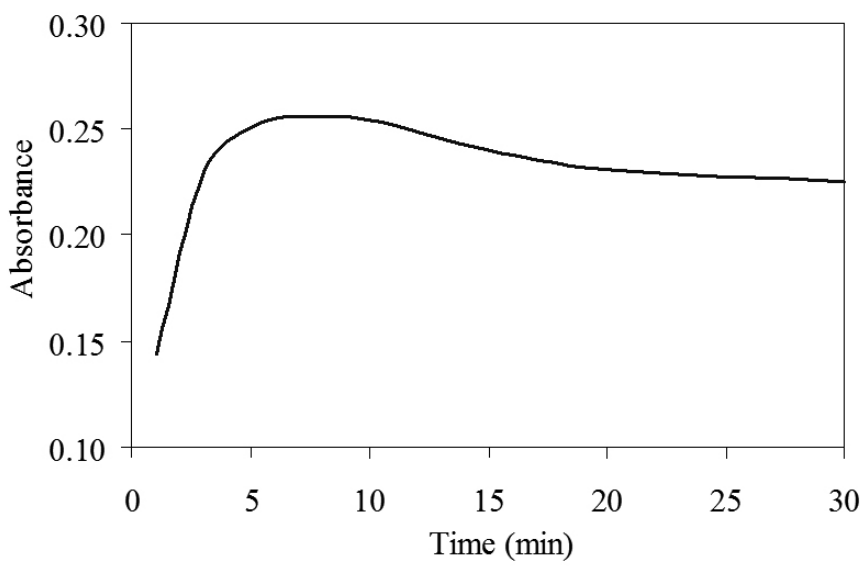

Figure 2. Time dependant absorbance

\subsection{Impact of reagent}

The method of photometric titration proved the reaction ratio CS vs Ellman's reagent being 1:1. Concerning practical reasons, the reagent concentration in the measured solution $200 \mu \mathrm{g} \mathrm{mL} \mathrm{m}^{-1}$ was used in order to shift maximally the balance in favour of an analytical reaction. The higher concentration had a negative impact on the colouration of a blank sample.

Ammonium acetate had a versatile impact on the progress of analysis. Most likely, it (i) participated on the catalytic dissociation of CS to malononitrile, (ii) ensured optimal reaction environment, (iii) eliminated interference and (iv) increased the speed of the reaction and the stability of colouration. The final concentration of ammonium acetate in the measured solution was $500 \mu \mathrm{g} \mathrm{mL}$

${ }^{1}$. The higher concentration (although, reaching at most $1000 \mu \mathrm{g} \mathrm{mL} \mathrm{mL}^{-1}$, which is given by the solubility limit of ammonium acetate in DMF) increased the reaction rate and the absorbance values, but significantly decreased the stability of the colour. The considerably lower concentration of ammonium acetate (below $250 \mu \mathrm{g} \mathrm{mL}^{-1}$ ) distinctively statistically worsened practically all relevan parameters of the method.

\subsection{Impact of solvent}

The aprotic solvent DMF was necessary for the correct development of the analytical reaction (including a deeper hue of the reaction product) and appeared to be also as an effective extraction reagent. The disadvantage of DMF is its higher toxicity and therefore, a possibility to replace it with a different aprotic solvent (DMSO) was verified. The use of DMSO was proven to be unsuitable, as it caused a distinct colouration of a blank experiment $(A=0.140$ with the addition $1 \mathrm{~mL}$ in the measured solution). Apart from that, the impact of water, ethanol and chloroform on the colouration system was studied. These solvents considerably decreased the measured values of absorbance; the toleration limits for separate solvents (at $\lambda_{\max }=501 \mathrm{~nm}$ ) were $1 \%$ (water), $2 \%$ (ethanol) and $5 \%$ (chloroform)

\subsection{Interference}

The interferences of several other compounds to determine CS via the developed method were studied. Concerning the fact that Ellman's reagent is highly sensitive to reduction substances ${ }^{20}$, sulphides, sulphites and thiols proved to have the highest interference recorded. On the other hand, the method proved to be highly resilient against the interference of commonly used riot control agents chloroacetophenone $(\mathrm{CN})$ and dibenz $[b, f][1,4]$ oxazepine $(\mathrm{CR})$. The list of the selected interferences is given in the Table 1 .

Table 1. Impact of interfering agents on absorbance; CS concentration in all samples is $4 \mu \mathrm{g} \mathrm{mL}^{-1}(\mathrm{~A}=0.340)$

\begin{tabular}{|c|c|c|}
\hline Substance & $\begin{array}{c}\text { Concentration / } \\
\boldsymbol{\mu g} \mathbf{~ m L}^{-1}\end{array}$ & Absorbance \\
\hline Sodium sulphide & 0.2 & 0.355 \\
\hline Sodium sulphite & 1 & 0.362 \\
\hline 2-(diisopropylamino)ethanethiol & 1 & 0.370 \\
\hline Phenol & 20 & 0.333 \\
\hline 2-Chloroethyl ethyl sulphide & 80 & 0.300 \\
\hline Dibenz[b,f][1,4]oxazepine & 80 & 0.340 \\
\hline Chloroacetophenone & 200 & 0.341 \\
\hline Thiodiglycol & 200 & 0.350 \\
\hline Citric acid & 1,000 & 0.345 \\
\hline$N, N$-dimethylethanolamine & 100,000 & 0.349 \\
\hline
\end{tabular}

\subsection{Analytical data}

The validity of the Lambert-Beer law was determined in the concentration range of $0.34-10.20 \mathrm{ug} \mathrm{mL}^{-1}$; the molar absorption coefficient of the colouring system was $1.37 \times 10^{3} \mathrm{~L} \mathrm{~mol}^{-1} \mathrm{~cm}^{-1}$ and Sandell's sensitivity $0.014 \mu \mathrm{g} \mathrm{cm}^{-2}(\mathrm{~A}=0.001)$. The median value of absorbance and standard deviation of $0.8 \mu \mathrm{g} \mathrm{mL}^{-1} \mathrm{CS}(\mathrm{n}=10)$ were 0.061 and 0.004 , respectively. The detection limit and correlation coefficient (r) were $0.18 \mu \mathrm{g} \mathrm{mL}^{-1}$ and 0.998 , respectively. The good reproducibility of the method was verified by comparing results obtained in two laboratories. 
Comparison of detection limits (and other parameters) of proposed method and other spectrophotometric methods presents Table 2.

Table 2. Overview of selected spectrophotometric methods for the determination of CS

\begin{tabular}{|c|c|c|c|c|}
\hline Method/reagent & $\lambda_{\max }, \mathbf{n m}$ & $\begin{array}{c}\text { Detection limit, } \\
\mu \mathrm{g} \mathrm{m \textrm {m } ^ { - 1 }}\end{array}$ & $\begin{array}{l}\text { Chloroacetophenone } \\
\text { interference }\end{array}$ & Reaction medium \\
\hline Chloranil & 662 & 3 & No & Water/ethanol \\
\hline 4-(4'-nitrobenzyl)pyridine & 482 & 2,5 & Yes & Water/ethanol \\
\hline 1,3-dinitrobenzene & 432 & 1 & Yes & Water/ethanol \\
\hline Sodium nitroprusside & 524 & 0.5 & Yes & Water/ethanol \\
\hline Marquis reagent & 400 & 0.5 & Yes & Sulphuric acid \\
\hline Benzofurazan oxid & 580 & 0.5 & Yes & Water/ethanol \\
\hline Fast Blue B & 420 & 0.4 & No & Chloroform \\
\hline Proposal method & 501 & 0.2 & No & DMF \\
\hline
\end{tabular}

\subsection{Sample and reagent stability}

The stability of the sample of CS in DMF was verified by repeating of the experiment after 24 hours. Stored at laboratory temperature and without the access of light, the sample was stable for at least 24 hours. When exposed to light, the sample gradually degraded. The higher stability was achieved while keeping the sample at the lower temperature $\left(4{ }^{\circ} \mathrm{C}\right)$. Ellman's reagent in DMF was stable for 24 hours (at $4{ }^{\circ} \mathrm{C}$ for several weeks) and in ammonium acetate even for several months. The mixture of Ellman's reagent and ammonium acetate in DMF was used only for several hours.

\subsection{Real samples application}

The results of the analysis of real samples indicate that the amount of CS in soil and brickwork was lower than the amount inserted (Table 3). This fact can be explained due to the losses during filtration. On the other hand, completely different results were achieved in the samples with silica gel $(108.8 \%$ recovery). During the extraction from glass wool, everything ran smoothly and the difference between the inserted and detected amount of CS was in the range of statistical error.

Table 3. Determination results of CS in real samples.

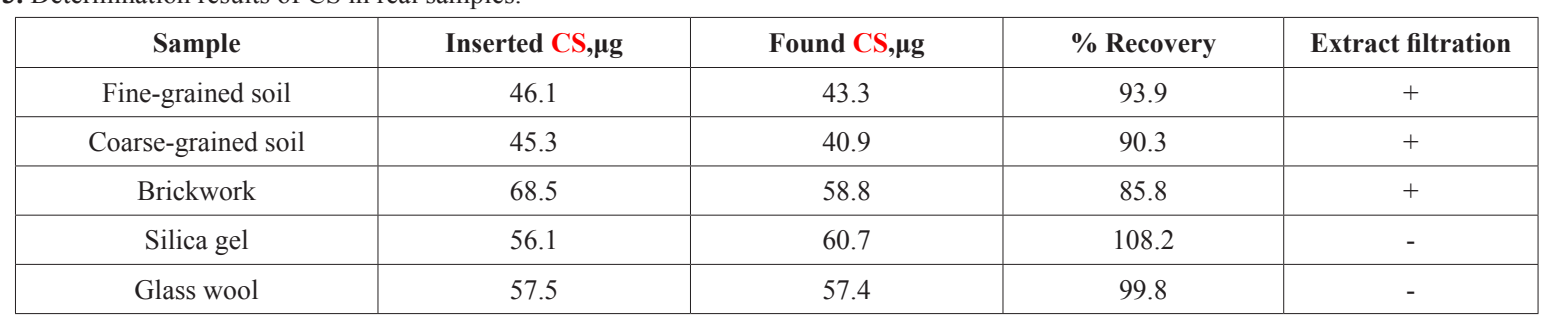

\section{CONCLUSIONS}

The new method of the spectrophotometric determination of CS in the solid samples of various origins and compositions using Ellman's reagent in the presence of ammonium acetate and in the environment of aprotic solution DMF is simple, sensitive, reproducible and cost-effective. All reagents are easily accessible even though the higher toxicity of DMF and the lower stability of CS in this dissolving agent are seen as a disadvantage. The critical point of the procedure is the extraction and preparation of a sample to be measured, which is highly connected to the character of an analysed sample. The method is suitable for the analysis in laboratory as well as field conditions. It widens the analytical usage of widely popular Ellman's reagent and allow to determine $\mathrm{CS}$ in the presence of other common riot control agents.

\section{REFERENCES}

1. Y. Dimitroglou Y., Rachiotis G., Hadjichristodoulou C., Int. J. Environ. Res. Public Health 14, 1397 (2015).

2. E. J. Olajos, W. Stopford. Riot control agents: Issues in toxicology, safety \& health. CRC Press, Boca Raton, 2004.

3. S. L. Hoenig. Compendium of chemical warfare agents. Springer, New York, 2007.

4. A. A. Druzhinin, N. E. Kaurov, S. A. Nemkov, V. A. Ishutin, J. Anal. Chem. 65, $1242(2010)$

5. J. A. Gag, N. F. Merck, J. Forensic Sci. 22, 358 (1977).

6. K. E. Ferslew, R. H. Orcutt, A. N. Hagardorn, J. Forensic Sci. 31, 658 (1986).

7. J. J. Hout, G. L. Hook, P. T. LaPuma, D. W. White, J. Occup. Environ. Hyg. 7, $352(2010)$.
8. J. J. Hout, T. Kluchinsky, P. T. LaPuma, D. W. White, J. Environ. Health 74, 18 (2011).

9. X. Lei, A. Q. Luo, Z. B. Sun, S. Yang, L. Q. Sun, Advanced Materials Research 1081, 75 (2014).

10. E. Halámek, Z. Kobliha, V. Pitschmann. Analysis of chemical warfare agents. University of Defence, Brno, 2009.

11. F. M. Issa, Y. M. Issa, H. Z. Youssef, R. M. Issa, Z. Anal. Chem. 277, $125(1975)$.

12. A. Stachlewska-Wroblowa, Biul, Wojsk. Akad. Tech. 21, 109 (1972)

13. Z. Makles, Chem. Anal. (Warsaw) 40, 755 (1995).

14. W. D. Ludemann, M. H. Stutz, S. Sass, Anal. Chem. 41, 679 (1969).

15. M. Haddadin, U. Khalidi, N. Turjuman, R. Ghougassian, Anal. Chem. 46, 2072 (1974). 16. M. Sokolowski, J. K. Różylo, J. Planar. Chromatogr. 6, 467 (1993).

17. E. Halámek, Z. Kobliha, Collect. Czech. Chem. Commun. 57, 1221 (1992).

18. V. Pitschmann, Chem. Listy 91, 125 (1997).

19. T. Nowicka-Jankowska, K. Gorczynska, A. Michalik, E. Wietska. Analytical visible and ultraviolet spectrometry. Elsevier Science, Amsterdam, 1985

20. G. L. Ellman, Arch. Biochem. Biophys. 82, 70 (1959). 